Article

\title{
Investigation of Karst Spring Flow Cessation Using Grey System Models
}

\author{
Yaru Guo ${ }^{1,2}$, Tian-Chyi Jim Yeh ${ }^{2,3}$ and Yonghong Hao ${ }^{2, *}$ \\ 1 School of Geographic and Environmental Sciences, Tianjin Normal University, No. 393 Binshuixi Road, \\ Xiqing District, Tianjin 300387, China; guoyaru0612@126.com \\ 2 Tianjin Key Laboratory of Water Resources and Environment, Tianjin Normal University, No. 393 Binshuixi \\ Road, Xiqing District, Tianjin 300387, China; yeh@hwr.arizona.edu \\ 3 Department of Hydrology and Water Resources, The University of Arizona, John Harshbarger Building, \\ 1133 E. North Campus Drive, Tucson, AZ 85721-0011, USA \\ * Correspondence: haoyh@sxu.edu.cn; Tel.: +86-139-2025-5628
}

Received: 9 July 2019; Accepted: 12 September 2019; Published: 15 September 2019

check for updates

\begin{abstract}
Karst aquifers are prominent sources of water worldwide; they store large amounts of water and are known for their beautiful springs. However, extensive groundwater development and climate variation has resulted in a decline in the flow of most karst springs; some have even dried up. In order to obtain a better understanding of the factors contributing to this development, this study introduced grey system models, which quantified spring flow, taking Jinci Springs (China), which dried up in May 1994, as an example. Based on the characteristics of Jinci Springs, spring flow was divided into two stages: first (1954-1960), when the spring flow was affected only by climate variation; and second (1961-1994), when the flow was impacted by both climate variation and anthropogenic activities. The results showed that Jinci Springs flow had a strong relationship with precipitation occurring one year and three years earlier in the first stage. Subsequently, a grey system GM $(1,3)$ model with one-year and three-year lags was set up for the first stage. By using the GM $(1,3)$ model, we simulated the spring flow in the second stage under effects of climate variation only. By subtracting the observed spring flow from the simulated flow, we obtained the contribution of anthropogenic activities to Jinci Springs' cessation. The contribution of anthropogenic activities and climate variation to the decline was $1.46 \mathrm{~m}^{3} / \mathrm{s}$ and $0.62 \mathrm{~m}^{3} / \mathrm{s}$, respectively. Finally, each human activity that caused the decline was estimated. The methods devised herein can be used to describe karst hydrological processes that are under the effects of anthropogenic activities and climate variation.
\end{abstract}

Keywords: Jinci Springs; drying-up; anthropogenic activities

\section{Introduction}

Karst aquifers store abundant groundwater and form a large number of karst springs; a few examples are Silver Spring (US), Dragonera Spring (Italy), Durzon Spring (France), Arjan Spring (Iran), and Niangziguan Spring (China) [1-4]. Generally, karst springs are the source of rivers and supply water to downstream regions, which is vital for economic development, especially in regional ecological environments. However, extensive groundwater development and climate variation have caused a decline in karst groundwater levels and spring flow, even drying up in many parts of the world, such as the Ras El Ain spring in Syria [5], the dolomitic springs in the Republic of South Africa (i.e., the Venterspost Eye and the Oberholzer Eye) [6,7], and some karst springs in Greece and Australia [8-10]. In northern China, the situation is grim with the drying up of Jinci Springs, Lancun Springs, Gudui Springs, Heilongdong Springs, and Zhougong Springs [11]. 
Scientists have been focusing on protecting groundwater in karst areas in an effort to propel sustainable groundwater development. Ozdemir [12] used a stable isotope to understand the physical process of influencing water flow in a karst area, and determined the location and residence time of groundwater recharge area in the Namazgah Dam Basin in Turkey; it was conducive to the identification of karst aquifer protection areas and the sustainable management of water resources. Sappa et al. [13] proposed a simple linear model based on the relationship between rainfall and discharge to simulate the effects of rainfall change on the minimum discharge of the Capodacqua di Spigno spring. This model was used for water resource management and planning in Italy. Using the normalization method, Abou Zakhem and Kattaa [5] analyzed the annual discharge and precipitation of the Ras El Ain spring. The results showed that the drying up of the spring may be a consequence of human activities. Therefore, sustainable water resource management schemes were developed to minimize the impact of over-exploitation on spring flow.

Jinci Springs was representative of karst springs in northern China. Cessation of its flow in May 1994 attracted public attention and promoted scientific research. Previous studies mainly focused on the spring's depletion and reoccurring conditions. Guo et al. [14] analyzed the reasons for the attenuation of a large karst spring flow in Shanxi from three aspects: atmospheric precipitation, coal mining, and groundwater overexploitation. In order to study the relationship between spring flow and precipitation, Hao et al. [15] proposed a correlation analysis method with time lag to distinguish the effects of precipitation variation and human factors on the drying up of Jinci Springs. Li et al. [16] analyzed the sensitivity of groundwater level in the Jinci Springs basin to anthropogenic activity, using an artificial neural network model. Their results showed that coal mining drainage was the most significant human factor that influenced the groundwater level in the Jinci Springs basin.

Sun et al. [17] used fuzzy linear regression to predict the reoccurring time of Jinci Springs flow under different scenarios. To predict the karst groundwater level of the Jinci Springs catchment from 2014 to 2020, Shi et al. [18] established a multiple linear regression model. The results indicated that the flow of water in Jinci Springs had the possibility of restarting prior to 2017 under a project to reduce groundwater exploitation. To investigate groundwater recovery in the Jinci Springs catchment, Lv et al. [19] divided the 1961-2012 groundwater level data into decline and recovery phases. The results highlighted the possibility of remarkable water resumption in the Jinci Springs catchment.

Differing from previous research, this study investigates the causes of Jinci Springs' decline using the grey system theory. We intend to modify the traditional grey relational analysis to determine the time lags between spring flow and precipitation. Subsequently, we try to quantify the effects of human activities on the cessation using a grey system GM $(1, \mathrm{~N})$ model with time lag. Finally, the human activities that caused the decline are studied and estimated.

\section{Study Area and Data Acquisition}

\subsection{Geographical Location and Background of Jinci Springs}

Jinci Springs is located in the northwest of Taiyuan Basin, Shanxi Province, China (Figure 1). The spring catchment is $2030 \mathrm{~km}^{2}$, including the exposed karst area of $391 \mathrm{~km}^{2}$ in the north and the buried karst area of $1639 \mathrm{~km}^{2}$ in the south. The topography is dominated by hills (Figure 1), and the terrain is higher in the northwest part of the catchment than in the southeast. The main administrative regions include Gujiao City, Qingxu County, and parts of Taiyuan City.

Jinci Springs was representative of karst springs in northern China; however, its flow ceased in May 1994. Prior to 1960, the spring's catchment was an undeveloped rural area. The local residents mainly used surface water, and human impacts on groundwater were negligible. The region gradually welcomed heavy industries, which included coal mines, chemical plants, and power plants. Subsequently, groundwater consumption increased, resulting in intensive exploitation of the resource. Subsequently, regional karst groundwater levels declined, leading to the drying up of Jinci Springs [15,19]. 


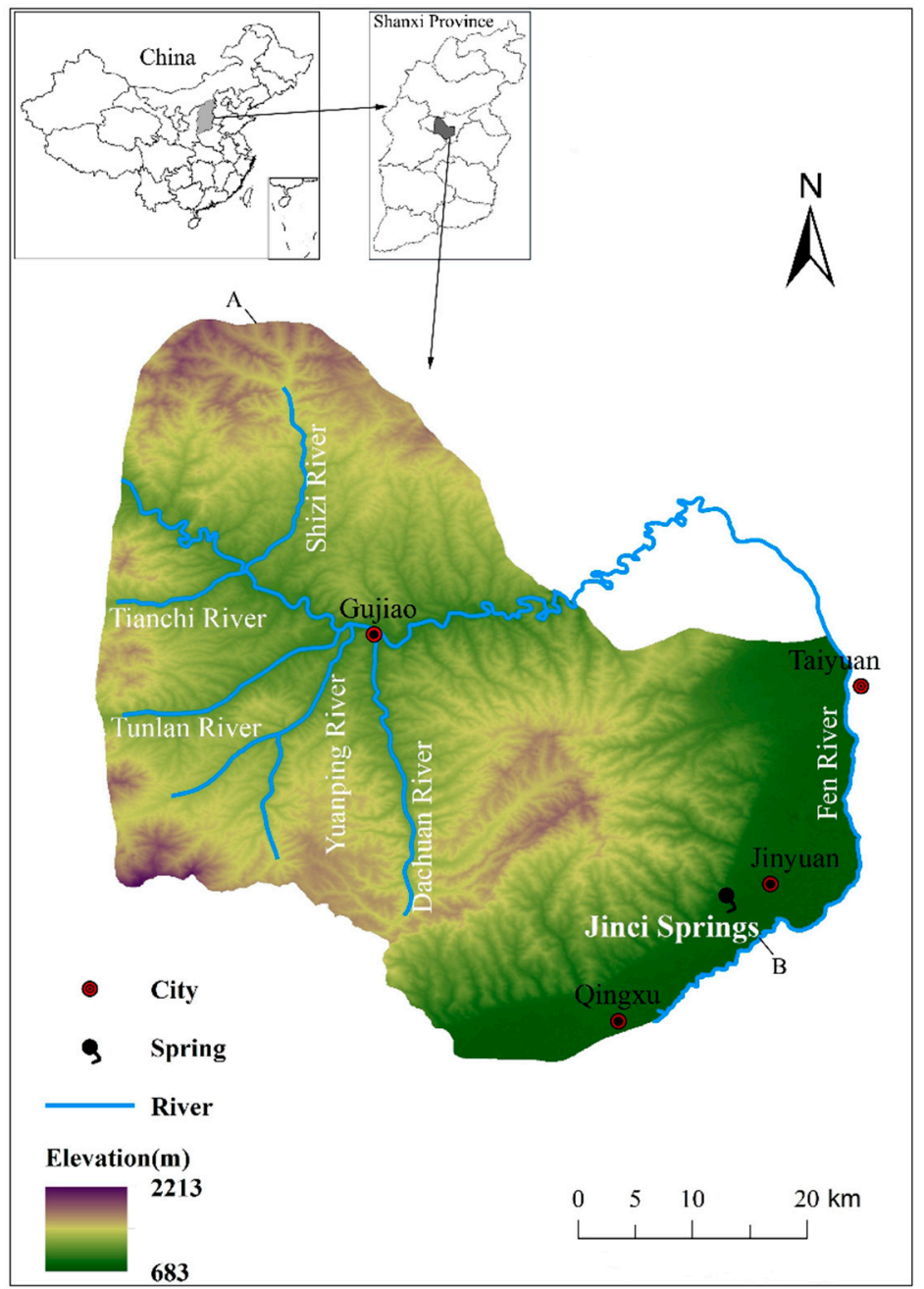

Figure 1. Location and digital elevation model (DEM) of the Jinci Springs catchment.

\subsection{Climatic Conditions of Jinci Springs}

The Jinci Springs area has a typical temperate, semi-arid, continental monsoon climate. The annual average precipitation in this area is $472 \mathrm{~mm}$ (1955-2015), and the distribution of precipitation is extremely uneven. The precipitation in a pluvial year is three times greater than that of a drought year. Sixty percent of the precipitation is concentrated in June to September (the flood season), higher in the mountainous area that in the basins.

Annual average temperature in the area is $8.1^{\circ} \mathrm{C}$, annual average evaporation is $1871.8 \mathrm{~mm}$, and annual average relative humidity is $60 \%$. Maximum thickness of the frozen soil layer is $1.1 \mathrm{~m}$, and the frost-free period is about 160 days. The dominant wind direction is northwest in winter and spring, and southeast in summer and autumn.

\subsection{Hydrogeological Conditions of Jinci Springs}

The main strata of the Jinci Springs catchment include Cambrian dolomite rocks, Ordovician carbonate rocks, Carboniferous and Permian coal seams, and Quaternary deposits (Figure 2). The karst system in Ordovician carbonate strata provides large spaces (i.e., pores, fractures, and conduits) for groundwater storage, and is thus the main aquifer. The exposed Ordovician carbonate rock in the north of Fenhe River, on the other hand, is the main groundwater recharge area; and in the south, is the groundwater runoff area, where the karst aquifers are buried and confined. Jinci Springs was the outlet for groundwater in the catchment. Precipitation infiltrates the exposed carbonate rocks in the 
north of Fenhe River, the groundwater flows to the southeast, and it discharges at Jinci Springs, where the groundwater encounters the impermeable formation. In addition, leakage of the Fenhe River also recharges the groundwater in the catchment [20].

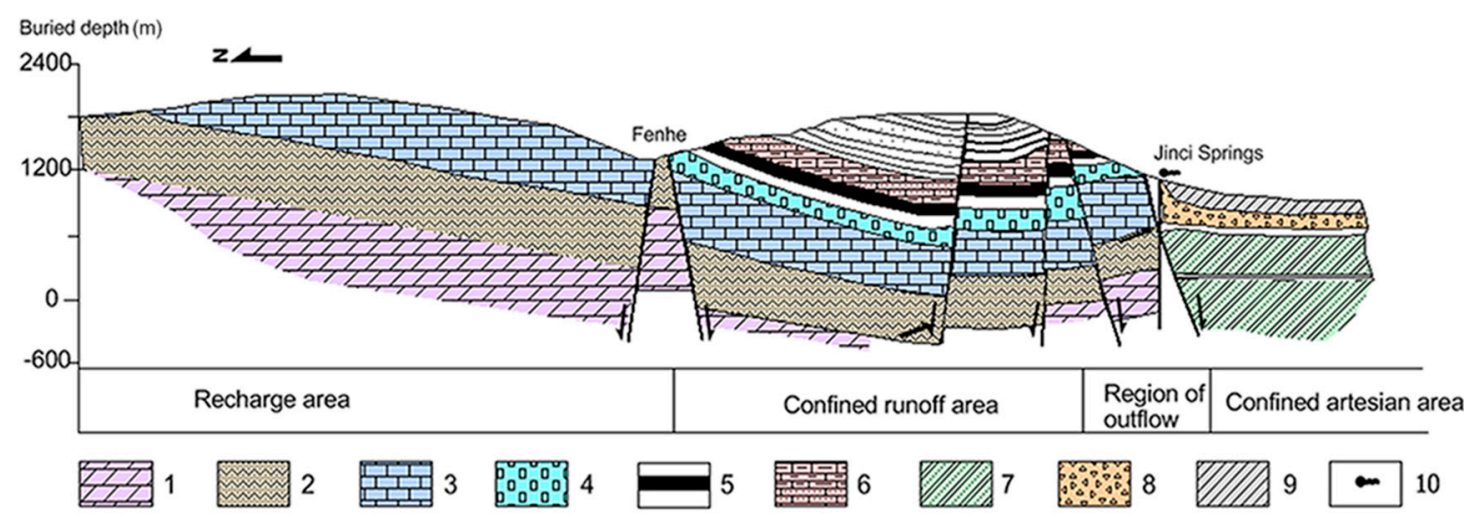

Figure 2. Geological cross-section of the Jinci Springs catchment, corresponding to A-B in Figure 1. 1. Cambrian dolomite rock, 2. Marl mingled with breccia, 3. Ordovician carbonate rock, 4. Bauxite,

5. Carboniferous and Permian coal seam, 6. Sand shale and coal-bearing strata, 7. Quaternary deposit,

8. Sandy conglomerate, 9. Clay, 10. Springs.

\subsection{Data Acquisition}

Jinci Springs flow was studied at the Jinci Hydrological Gauge Station from 1954 to May 1994 (i.e., the time it ceased), and spring flow was quantified by a flow measuring weir. Precipitation data from 1950 to 1995 were collected at Jinci Meteorological Gauge Station. The annual average spring flow and annual precipitation data are shown in Figure 3.

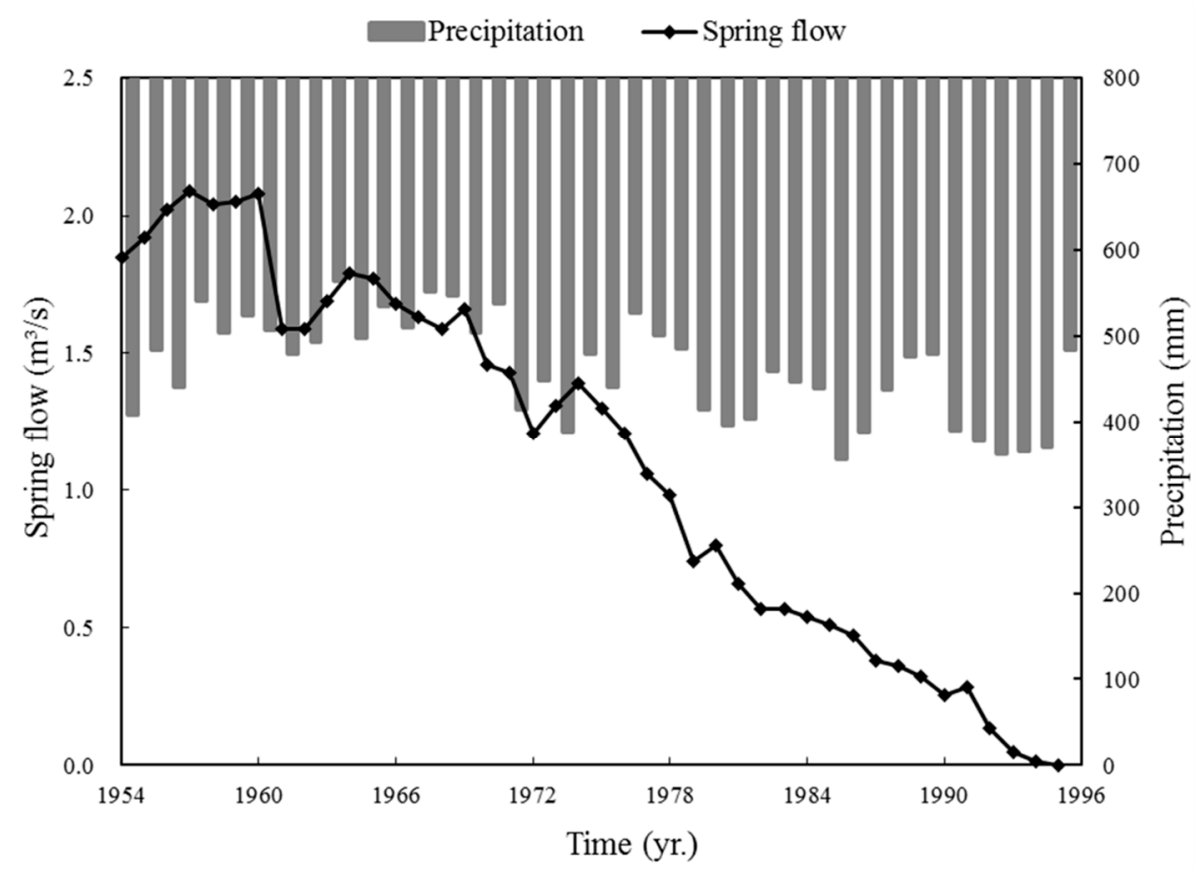

Figure 3. Spring flow and precipitation of Jinci Springs.

\section{Methods}

A grey system refers to a method where some information is known and some are unknown or uncertain (i.e., a system with incomplete information) [21,22]. The karst groundwater system is 
affected by multiple factors, some of which are not completely known. Therefore, it can be considered a grey system [23-25], and the reason why the grey system method is used in this study.

\subsection{Grey Relational Analysis with Time Lag}

Grey relational analysis is a grey system method that has been widely applied in various fields, such as economics [26], sociology [27] and environics [28]. Its basic idea is to determine the relational degree between two data sequences, depending on the similarity of their geometric shapes [29]. The closer the geometric shapes between data sequences, the larger the relational degree is.

In karst hydrological processes, there exists a time lag between spring flow and precipitation. Because of the filtering effects of aquifers, the infiltrated precipitation takes time to reach spring outlets, causing delayed responses in spring flow. This time lag is regarded as a hydraulic response time. Therefore, we introduce the concept of time lag into the traditional grey relational analysis. In this model, spring flow is the characteristic sequence of the system, and precipitation is the related factor sequence. Subsequently, the relational degrees between spring flow and precipitation with different time lags are calculated. When the relational degree is the maximum, the corresponding time lag is the hydraulic response time of the aquifer.

Let the time sequence of system behavior characteristics be $Q(t)(t=1,2, \cdots, n)$ (e.g., spring flow), and the relational sequence with time lag $i$ be $R_{i}(t-i)(i=0,1, \cdots, m)$ (e.g., precipitation). In order to nondimensionalize for behavior and relational sequences, we implement an initialization operation for $Q(t)$ and $R_{i}(t-i)$ :

$$
\widetilde{Q}(t)=\frac{Q(t)}{Q(1)}, t=1,2, \cdots, n
$$

where $\widetilde{Q}(t)$ is the initialized system behavior characteristic sequence.

$$
\widetilde{R}_{i}(t-i)=\frac{R_{i}(t-i)}{R_{i}(1-i)}, t=1,2, \cdots, n ; i=0,1, \cdots, m
$$

where $\widetilde{R}_{i}(t-i)$ is the initialized relational sequence.

The absolute value sequence of the difference between the corresponding components of $\widetilde{Q}(t)$ and $\widetilde{R}_{i}(t-i)$ is:

$$
\Delta_{i}(t)=\left|\widetilde{Q}(t)-\widetilde{R}_{i}(t-i)\right|, t=1,2, \cdots, n, i=0,1, \cdots, m
$$

Then, we calculate the grey relational coefficient of $Q(t)$ with respect to $R_{i}(t-i)$ :

$$
\gamma_{Q R_{i}}(t)=\frac{m+\xi M}{\Delta_{i}(t)+\xi M}, \xi \in(0,1) ; t=1,2, \cdots, n ; i=0,1, \cdots, m
$$

where $M=\operatorname{maxmax}_{i} \Delta_{i}(t), m=\operatorname{minmin}_{i} \Delta_{i}(t)$ and $\xi$ is defined as a distinguishing coefficient, generally $\xi=0.5$.

The degree of grey relational of $Q(t)$ with respect to $R_{i}(t-i)$ is defined as:

$$
\gamma_{Q R_{i}}=\frac{1}{n} \sum_{t=1}^{n} \gamma_{Q R_{i}}(t), i=0,1, \cdots, m
$$

The degrees of grey relational $\gamma_{Q R_{i}}$ with time lags $i=0,1, \cdots, m$ can be acquired. Generally, the influencing factors of $\gamma_{Q R_{i}}>0.70$ are defined as strong influencing factors. $0.60 \leq \gamma_{Q R_{i}} \leq 0.70$ are general, and $\gamma_{Q R_{i}}<0.60$ are weak. We set the time lag $i$ corresponding to the $\gamma_{Q R_{i}}>0.70$ between $Q(t)$ and $R_{i}(t-i)$ as $\tau_{j}(j=1,2, \cdots, N)$. 


\subsection{Grey System GM $(1, N)$ Model with Time Lag}

The grey system prediction model is also called the GM model. The GM $(1, N)$ model represents a differential equation model with 1 order and $N$ variables [26]. In order to simulate spring flow, we establish GM $(1, \mathrm{~N})$ model with time lag $\tau_{j}(j=1,2, \cdots, N)$. In the model, it is assumed that $Q^{(0)}(t)$ $(t=1,2, \cdots, n)$ is the sequence of system characteristics (e.g., spring flow), $R_{j}^{(0)}\left(t-\tau_{j}\right)(j=1,2, \cdots, N)$ is the relational sequence (e.g., precipitation), $\tau_{j}$ is time lag between two sequences (e.g., time lag between precipitation and spring flow).

Let

$$
\begin{gathered}
Q^{(1)}(t)=\sum_{k=1}^{t} Q^{(0)}(k), t=1,2, \cdots, n \\
R_{j}^{(1)}(t-\tau)=\sum_{k=1}^{t} R_{j}^{(0)}\left(k-\tau_{j}\right), t=1,2, \cdots, n ; j=1,2, \cdots, N
\end{gathered}
$$

be the first-order accumulated generating operation (1-AGO) sequences of $Q^{(0)}(t)$ and $R_{j}^{(0)}\left(t-\tau_{j}\right)$.

Then, the differential equation is established as follows:

$$
\frac{d Q^{(1)}(t)}{d t}+a Q^{(1)}(t)=\sum_{j=1}^{N} b_{j} R_{j}^{(1)}\left(t-\tau_{j}\right)
$$

Let us use the least squares estimation to solve the parameter vector $\hat{a}$, which is expressed as:

$$
\begin{gathered}
\hat{a}=\left[a, b_{1}, b_{2}, \cdots b_{N}\right]^{T}=\left(B^{T} B\right)^{-1} B^{T} Y \\
\text { Where } B=\left\{\begin{array}{cccc}
-\frac{1}{2}\left[Q^{(1)}(2)+Q^{(1)}(1)\right] & R_{1}^{(1)}\left(2-\tau_{1}\right) & \cdots & R_{N}^{(1)}\left(2-\tau_{N}\right) \\
-\frac{1}{2}\left[Q^{(1)}(3)+Q^{(1)}(2)\right] & R_{1}^{(1)}\left(3-\tau_{1}\right) & \cdots & R_{N}^{(1)}\left(3-\tau_{N}\right) \\
\vdots & \vdots & \vdots & \vdots \\
-\frac{1}{2}\left[Q^{(1)}(n)+Q^{(1)}(n-1)\right] & R_{1}^{(1)}\left(n-\tau_{1}\right) & \cdots & R_{N}^{(1)}\left(n-\tau_{N}\right)
\end{array}\right\} \\
Y=\left[Q^{(0)}(2), Q^{(0)}(3), \cdots Q^{(0)}(n)\right]^{T}
\end{gathered}
$$

Then, we input the parameters of $\hat{a}$ to Equation (8) to solve the differential equation. The approximate time response solution is thus obtained:

$$
\hat{Q}^{(1)}(t+1)=\left\{Q^{(0)}(1)-\frac{1}{a}\left[\sum_{j=1}^{N} b_{j} R_{j}^{(1)}\left(t-\tau_{j}+1\right)\right]\right\} e^{-a t}+\frac{1}{a}\left[\sum_{j=1}^{N} b_{j} R_{j}^{(1)}\left(t-\tau_{j}+1\right)\right] \quad t=1,2, \cdots, n
$$

Subsequently, through inverse accumulation restoration, we can obtain the simulated values of the characteristic variable:

$$
\hat{Q}^{(0)}(t+1)=\hat{Q}^{(1)}(t+1)-\hat{Q}^{(1)}(t), t=1,2, \cdots, n
$$

\section{Results}

\subsection{Piecewise Analysis of the Jinci Springs flow}

The spring flow curve of Jinci Springs (Figure 3) shows two stages: 1954-1960 and 1961-1994. In the first stage (1954-1960), the spring flow varied steadily, only affected by climate variation. In the second stage (1961-1994), the spring flow declined rapidly, impacted by climate variation and anthropogenic activities. 
Based on the data of the first stage, we calculated the delay between spring flow and precipitation using the grey relational analysis with time lag, and then established the GM $(1, N)$ model with time lag, which describes Jinci Springs flow under the effects of climatic variation. Subsequently, we used the GM $(1, \mathrm{~N})$ model with time lag to simulate spring flow in the second stage.

It is worth noting that the simulated values represent the spring flow under the influence of climate variation only, and the observed values were the spring flow under the influence of both climatic variation and anthropogenic activities. Therefore, subtracting the observed values from the simulated values results in determining the contribution of anthropogenic activities to flow cessation in Jinci Springs.

\subsection{Grey Relational Degrees with Time Lag}

We selected the observed spring flow from 1956 to 1960 as a system characteristic sequence $Q(t)$ $(t=1,2, \cdots, 5)$ and precipitation in advance of spring flow 0 to 5 years as a relational sequence $R_{i}(t-i)$ $(t=1,2, \cdots, 5 ; i=0,1, \cdots, 5)$ to calculate the grey relational degrees with time lags of 0 to 5 years (Table 1). Karst aquifers are large groundwater reservoirs. After precipitation infiltrates a saturated aquifer through an epikarst, groundwater merges in the aquifer, and then discharges to the surface as spring. In the hydrological process of transforming precipitation signals into spring flow, the karst aquifer alters signals by buffering and merging. To reflect on the mechanism whereby a karst aquifer adjusts groundwater flow, we carried out a three-year moving average procedure for precipitation time series.

Table 1. Observed data of Jinci Springs flow and precipitation.

\begin{tabular}{|c|c|c|c|c|c|c|c|c|c|c|}
\hline Time (year) & 1951 & 1952 & 1953 & 1954 & 1955 & 1956 & 1957 & 1958 & 1959 & 1960 \\
\hline $\begin{array}{l}\text { Spring flow } \\
\left(\mathrm{m}^{3} / \mathrm{s}\right)\end{array}$ & & & & & & 2.02 & 2.09 & 2.04 & 2.05 & 2.08 \\
\hline \multirow{6}{*}{$\begin{array}{l}\text { Precipitation in } \\
\text { advance of } 0 \text { to } \\
5 \text { years }(\mathrm{mm})\end{array}$} & & & & & & 441.08 & 542.18 & 503.95 & 523.86 & \multirow[t]{6}{*}{507.24} \\
\hline & & & & & 485.26 & 441.08 & 542.18 & 503.95 & 523.86 & \\
\hline & & & & 409.67 & 485.26 & 441.08 & 542.18 & 503.95 & & \\
\hline & & & 452.27 & 409.67 & 485.26 & 441.08 & 542.18 & & & \\
\hline & & 602.92 & 452.27 & 409.67 & 485.26 & 441.08 & & & & \\
\hline & 685.92 & 602.92 & 452.27 & 409.67 & 485.26 & & & & & \\
\hline
\end{tabular}

Based on the data listed in Table 1, we used Equations (4) and (5) to calculate the grey relational degrees between the spring flow and precipitation under different time lags of 0 to 5 year. The results are shown in Table 2.

Table 2. Grey relational degrees between the spring flow and precipitation under different time lags.

\begin{tabular}{ccccccc}
\hline Time Lag (year) & 0 & 1 & 2 & 3 & 4 & 5 \\
\hline $\begin{array}{c}\text { Grey Relational } \\
\text { Degree }\end{array}$ & 0.6621 & 0.7980 & 0.6507 & 0.7559 & 0.5442 & 0.5345 \\
\hline
\end{tabular}

Table 2 shows that when time lags between precipitation and spring flow equal one year and three years, the grey relational degrees are larger than 0.70 , which means the Jinci Springs flow strongly correlated with precipitation in advance of one and three years. The results are consistent with the regional geological structure and reflects the heterogeneity of the stratums in the Jinci Springs catchment: the Ordovician karst aquifer is covered by Carboniferous and Permian coal seam, Triassic sand shale, and Quaternary loess sediment from the bottom up. Hydraulic connections between shallow groundwater and karst groundwater are made through fissures, faults, and conduits. These connections help precipitation infiltration to reach spring outlets in a short time (i.e., one year), as compared to others that take longer (i.e., three years). 


\subsection{The Grey System GM $(1, N)$ Model With Time Lag}

\subsubsection{Establishment of the GM $(1, \mathrm{~N})$ Model with Time Lag}

Because the Jinci Springs flow was mainly recharged by precipitation ahead of one year and three years, the GM $(1,3)$ model with time lags of one year and three years was established. Let the spring flow data from 1956 to 1960 be the original data series $Q^{(0)}(t)(t=1,2, \cdots, 5)$, the precipitation data ahead of the spring flow with one year and three years as the relevant factor $R_{1}^{(0)}(t-1)$ (i.e., precipitation from 1955 to 1959), and $R_{2}^{(0)}(t-3)$ (i.e., precipitation from 1953 to 1957). Taking precipitation as input and spring flow as output, we set up the GM $(1,3)$ model with one-year and three-year lags.

The results of the parameter identification for vector $\hat{a}$ in Equation (9) were as follows:

$$
\hat{a}=\left[a, b_{1}, b_{2}\right]^{T}=\left(\begin{array}{l}
3.3222 \\
0.0118 \\
0.0015
\end{array}\right)
$$

Then we can ensure that the model:

$$
\frac{d Q^{(1)}(t)}{d t}+3.3222 Q^{(1)}(t)=0.0118 R_{1}^{(1)}(t-1)+0.0015 R_{2}^{(1)}(t-3)
$$

The approximate time response sequence was:

$$
\begin{aligned}
& \hat{Q}^{(1)}(t+1)=\left[2.02-0.00355 R_{1}^{(1)}(t)-0.00045 R_{2}^{(1)}(t-2)\right] e^{-3.3222 t}+0.00355 R_{1}^{(1)}(t) \\
& +0.00045 R_{2}^{(1)}(t-2)
\end{aligned}
$$

Through inverse accumulation restoration, i.e., Equation (13), we obtained the simulated Jinci Springs flow (Table 3).

Table 3. Calibration for the GM $(1,3)$ model with one-year and three-year lags.

\begin{tabular}{ccccc}
\hline Year & $\begin{array}{c}\text { Observed Spring } \\
\text { Flow }\left(\mathbf{m}^{\mathbf{3}} / \mathbf{s}\right)\end{array}$ & $\begin{array}{c}\text { Simulated Spring } \\
\text { Flow }\left(\mathbf{m}^{3} \mathbf{s}\right)\end{array}$ & Residual & $\begin{array}{c}\text { Relative } \\
\text { Error }(\%)\end{array}$ \\
\hline 1956 & 2.02 & 2.02 & 0 & 0 \\
1957 & 2.09 & 1.60 & 0.49 & 23.46 \\
1958 & 2.04 & 2.20 & -0.16 & 7.83 \\
1959 & 2.05 & 1.99 & 0.06 & 2.74 \\
1960 & 2.08 & 2.11 & -0.03 & 1.24 \\
\hline
\end{tabular}

\subsubsection{Model Calibration}

The relative error was between $1.24 \%$ and $23.46 \%$, and the average relative error was $8.82 \%$. The model sufficiently passed the calibration.

\subsubsection{Simulation of Jinci Springs Flow in the Second Stage}

The GM $(1,3)$ model with one-year and three-year lags described the Jinci Springs flow under the influence of climate variation in the first stage. By substituting precipitation from 1958 to 1993 into the model, one can obtain the simulated spring flow from 1961 to 1994 under the effects of climate variation. By subtracting the observed spring flow from the simulated one, we can approximate the contribution of anthropogenic activities to the cessation of spring flow. The results are shown in Table 4 and Figure 4. 
Table 4. Contribution of anthropogenic activities to the drying up of Jinci Springs.

\begin{tabular}{|c|c|c|c|}
\hline Year & $\begin{array}{l}\text { Observed Spring Flow } \\
\qquad\left(\mathrm{m}^{3} / \mathrm{s}\right)\end{array}$ & $\begin{array}{l}\text { Simulated Spring Flow } \\
\qquad\left(\mathrm{m}^{3} / \mathrm{s}\right)\end{array}$ & $\begin{array}{c}\text { Contribution of Anthropogenic } \\
\text { Activities to Spring Flow } \\
\text { Cessation }\left(\mathrm{m}^{3} / \mathrm{s}\right)\end{array}$ \\
\hline 1961 & 1.59 & 2.03 & 0.44 \\
\hline 1962 & 1.59 & 1.94 & 0.35 \\
\hline 1963 & 1.69 & 1.99 & 0.30 \\
\hline 1964 & 1.79 & 2.22 & 0.43 \\
\hline 1965 & 1.77 & 1.99 & 0.22 \\
\hline 1966 & 1.68 & 2.16 & 0.48 \\
\hline 1967 & 1.63 & 2.04 & 0.41 \\
\hline 1968 & 1.59 & 2.21 & 0.62 \\
\hline 1969 & 1.66 & 2.17 & 0.51 \\
\hline 1970 & 1.46 & 2.04 & 0.58 \\
\hline 1971 & 1.43 & 2.16 & 0.73 \\
\hline 1972 & 1.21 & 1.70 & 0.49 \\
\hline 1973 & 1.31 & 1.84 & 0.53 \\
\hline 1974 & 1.39 & 1.57 & 0.18 \\
\hline 1975 & 1.30 & 1.90 & 0.60 \\
\hline 1976 & 1.21 & 1.75 & 0.54 \\
\hline 1977 & 1.06 & 2.09 & 1.03 \\
\hline 1978 & 0.98 & 1.98 & 1.00 \\
\hline 1979 & 0.74 & 1.96 & 1.22 \\
\hline 1980 & 0.80 & 1.70 & 0.90 \\
\hline 1981 & 0.66 & 1.63 & 0.97 \\
\hline 1982 & 0.57 & 1.62 & 1.05 \\
\hline 1983 & 0.57 & 1.81 & 1.24 \\
\hline 1984 & 0.54 & 1.77 & 1.23 \\
\hline 1985 & 0.51 & 1.77 & 1.26 \\
\hline 1986 & 0.47 & 1.47 & 1.00 \\
\hline 1987 & 0.38 & 1.58 & 1.20 \\
\hline 1988 & 0.36 & 1.72 & 1.36 \\
\hline 1989 & 0.32 & 1.87 & 1.55 \\
\hline 1990 & 0.25 & 1.90 & 1.65 \\
\hline 1991 & 0.29 & 1.60 & 1.32 \\
\hline 1992 & 0.14 & 1.56 & 1.43 \\
\hline 1993 & 0.05 & 1.46 & 1.42 \\
\hline 1994 & 0.01 & 1.47 & 1.46 \\
\hline
\end{tabular}

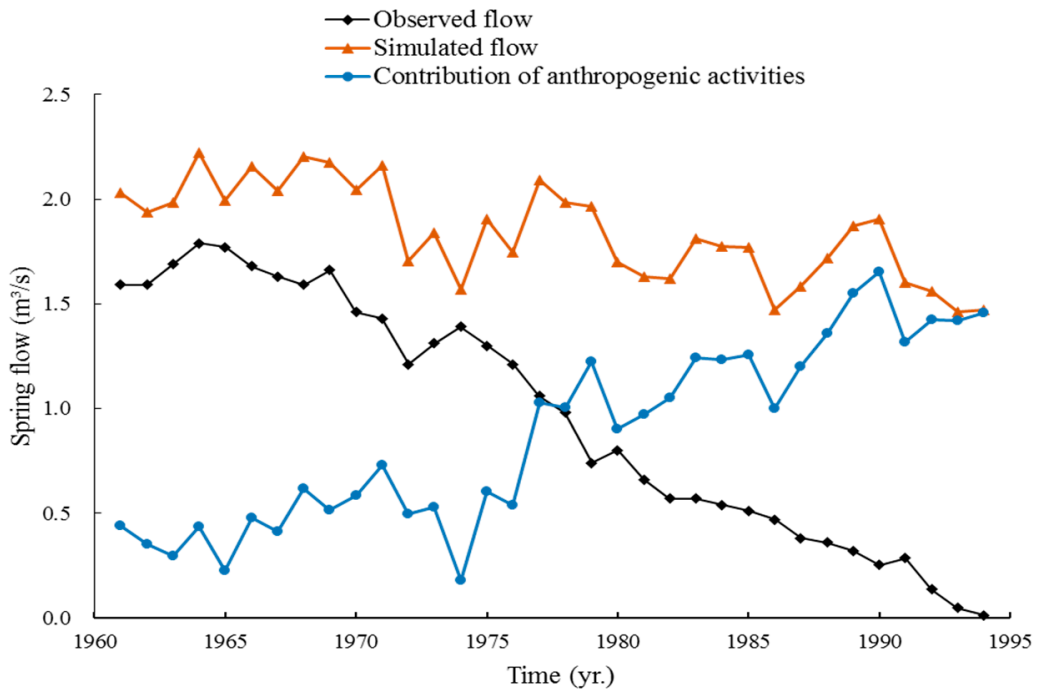

Figure 4. Contribution of anthropogenic activities to spring flow attenuation in Jinci Springs. 


\section{Discussion}

In Figure 4, the observed spring flow from 1961 to 1994 shows an obvious downward trend. Similarly, the simulated spring flow also showed a decline, but the declining rate was much smaller than that of the observed spring flow. Simultaneously, the contribution of anthropogenic activities to the spring flow attenuation had an uptrend.

The observed spring flow was $2.08 \mathrm{~m}^{3} / \mathrm{s}$ in 1960 (Table 1), and the Jinci Springs dried up in May 1994. Therefore, the total contribution of climate variation and anthropogenic activities to the Jinci Springs drying-up was $2.08 \mathrm{~m}^{3} / \mathrm{s}$. Moreover, the contribution of anthropogenic activities was $1.46 \mathrm{~m}^{3} / \mathrm{s}$ in 1994, accounting for $70 \%$ of the total contribution (Table 4). The contribution of climate variation was $0.62 \mathrm{~m}^{3} / \mathrm{s}$, accounting for $30 \%$. The contribution of anthropogenic activities had surpassed that of climate variation from 1960 to 1994, and anthropogenic activities became the dominant factor governing the spring flow. Because the Ordovician karst aquifer is covered by Carboniferous and Permian coal seams, Triassic shales, and Quaternary sediments from the bottom up, dewatering from coal mining decreased the groundwater recharge from karst aquifers, causing decline of the Jinci Springs flow. In addition, chemical and power plants directly pumped large amounts of groundwater from karst aquifers, which further aggravated the attenuation.

In order to acquire a better understanding of the influence of anthropogenic activities on the spring flow, we investigated the main human activities, and discussed the reasons for the cessation of the Jinci Springs flow.

\subsection{Karst Groundwater Exploitation}

In the 1950s, water supply was primarily dependent on surface water, and the effects of human activities on groundwater were negligible. In that period of time, climate variation was the dominant factor. However, a boom in regional economic development put a strain on surface water, and the utilization of karst groundwater gradually increased. From 1960 onwards, groundwater exploitation and the number of wells in karst aquifers in the Jinci Springs catchment rapidly increased (Figure 5). By 1994, the number of wells had reached 70 with pumping rate of $1.02 \mathrm{~m}^{3} / \mathrm{s}[11,30]$, an increase of $0.97 \mathrm{~m}^{3} / \mathrm{s}$ compared to 1960 .

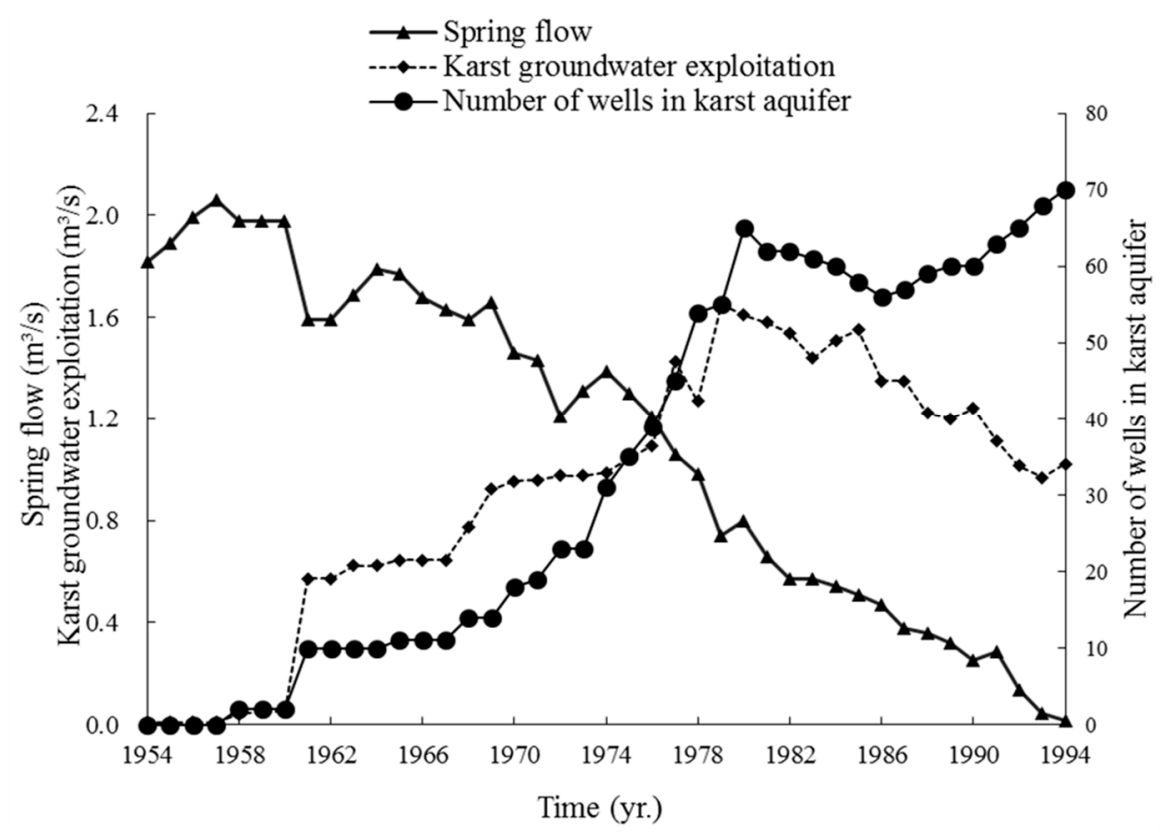

Figure 5. Spring flow, karst groundwater exploitation, and number of wells in the Jinci Springs catchment. 


\subsection{Dewatering from Coal Mining}

Dewatering from coal mining directly reduced the recharge available to the area's karst aquifers, causing the decline of the spring flow. The dewatering was $0.05 \mathrm{~m}^{3} / \mathrm{s}$ in 1960 and $0.65 \mathrm{~m}^{3} / \mathrm{s}$ in 1994 (Figure 6), an increase of $0.60 \mathrm{~m}^{3} / \mathrm{s}$ [30].

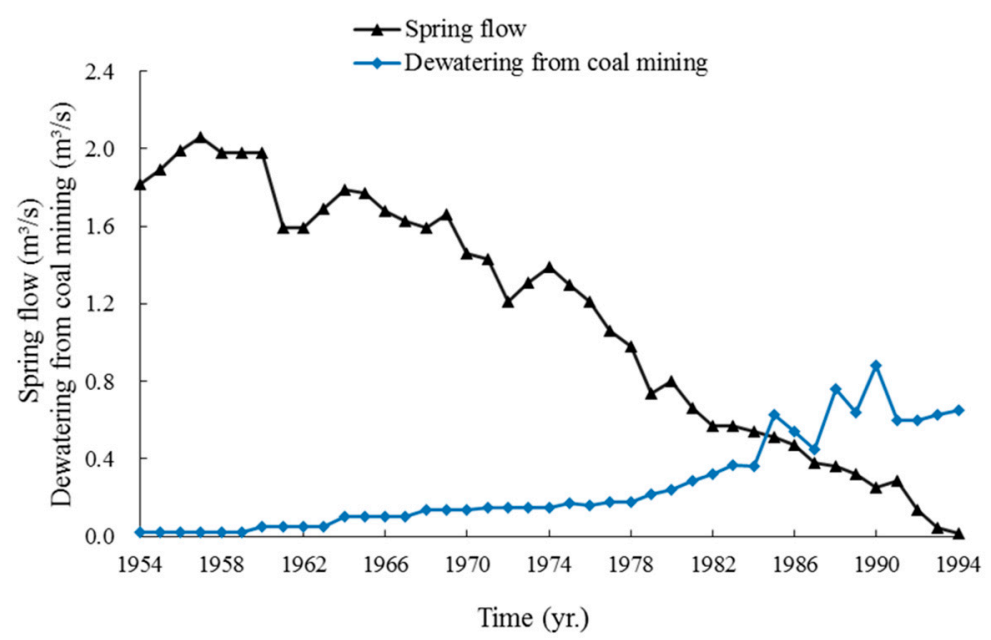

Figure 6. Spring flow and dewatering from coal mining in the Jinci Springs catchment.

\subsection{Construction of the Fenhe Reservoir}

Leakage from Fenhe River is a major source of water entering the karst aquifers in Jinci Springs [31]. In 1960, the leakage of Fenhe River was $4150 \times 10^{4} \mathrm{~m}^{3} / \mathrm{a}\left(1.32 \mathrm{~m}^{3} / \mathrm{s}\right)$. Completion of construction of the Fenhe Reservoir on the upper reaches of the Fenhe River resulted in a year-by-year reduction in runoff, and a subsequent reduction in leakage (Figure 7). In 1994, the leakage of Fenhe River was estimated to be $3550 \times 10^{4} \mathrm{~m}^{3} / \mathrm{a}\left(1.13 \mathrm{~m}^{3} / \mathrm{s}\right)$, a reduction of $0.19 \mathrm{~m}^{3} / \mathrm{s}$ [32] compared to 1960 .

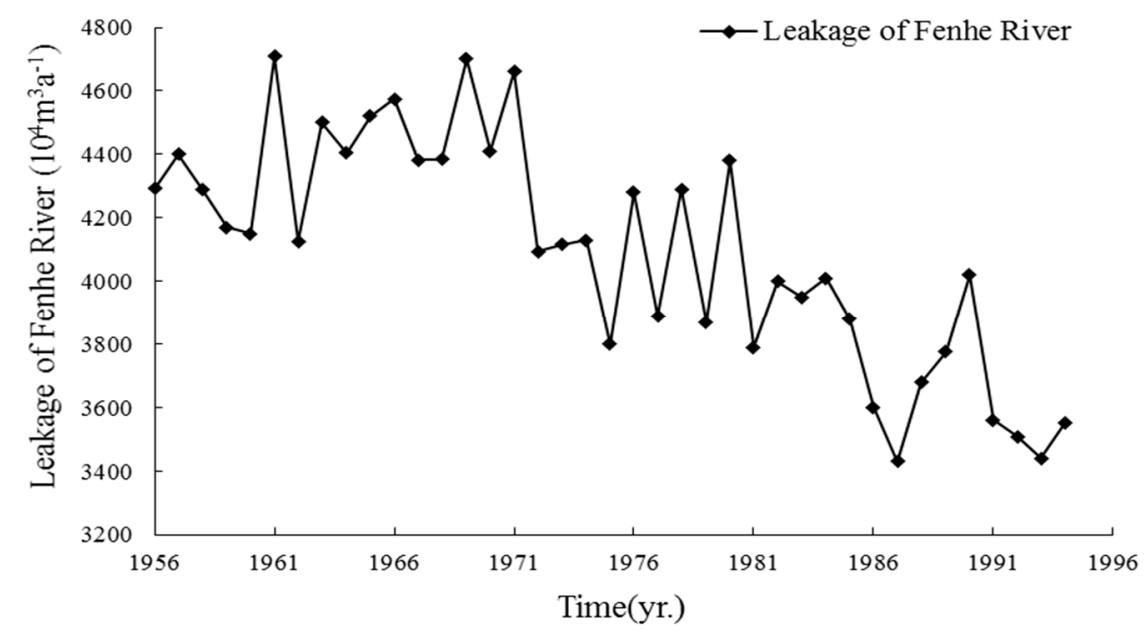

Figure 7. Leakage of Fenhe River.

In summary, there were three human activities that caused the drying-up of Jinci Springs. Groundwater exploitation increment was found to be $0.97 \mathrm{~m}^{3} / \mathrm{s}$, dewatering from coal mining increment was $0.60 \mathrm{~m}^{3} / \mathrm{s}$, and leakage reduction of Fenhe River was $0.19 \mathrm{~m}^{3} / \mathrm{s}$. The contribution of these activities to Jinci Springs' decline was $1.76 \mathrm{~m}^{3} / \mathrm{s}$. The actual contribution of human activities (i.e., $1.76 \mathrm{~m}^{3} / \mathrm{s}$ ) was larger than the simulated one (i.e., $1.46 \mathrm{~m}^{3} / \mathrm{s}$ ). In fact, the difference between the actual and simulated contributions (i.e., $0.30 \mathrm{~m}^{3} / \mathrm{s}$ ) was the result of further human exploitation of groundwater after the spring dried up in May 1994. 


\section{Conclusions}

The Jinci Springs flow had a strong correlation-it was recharged-with precipitation occurring one year and three years in advance. Owing to the effects of climate variation and anthropogenic activities, Jinci Springs dried up in 1994. The contribution of anthropogenic activities and climate variation to Jinci Springs cessation was found to be $1.46 \mathrm{~m}^{3} / \mathrm{s}$ and $0.62 \mathrm{~m}^{3} / \mathrm{s}$, accounting for $70 \%$ and $30 \%$, respectively. The influence of anthropogenic activities on the spring flow cessation surpassed climate variation and was the major factor.

Three major human activities caused the Jinci Springs decline. The contribution of groundwater exploitation increment was $0.97 \mathrm{~m}^{3} / \mathrm{s}$, dewatering from coal mining increment was $0.60 \mathrm{~m}^{3} / \mathrm{s}$, and leakage reduction of Fenhe River was $0.19 \mathrm{~m}^{3} / \mathrm{s}$. The total contribution was $1.76 \mathrm{~m}^{3} / \mathrm{s}$, which was larger than the critical value of human activities (i.e., $1.46 \mathrm{~m}^{3} / \mathrm{s}$ ). In other words, after the Jinci Springs dried up, human activities continued to overexploit groundwater by about $0.30 \mathrm{~m}^{3} / \mathrm{s}$, which was the difference between the actual contribution of human activities (i.e., $1.76 \mathrm{~m}^{3} / \mathrm{s}$ ) and the simulated contribution (i.e., $1.46 \mathrm{~m}^{3} / \mathrm{s}$ ). This points towards groundwater mining.

Spring flow decline is a global environmental problem caused by social and economic development. The methods described in this paper can be further used to describe karst hydrological processes that are under the effects of anthropogenic activities and climate variation, and can help create viable solutions.

Author Contributions: All authors contributed to the design and development of this manuscript: resources, Y.H.; data curation, Y.G.; writing—original draft preparation, Y.G.; writing-review and editing, Y.H. and T.-C.J.Y.

Funding: This work is partially supported by the Natural Science Foundation of Tianjin, China (grant number: 18JCZDJC39500), Program for Innovative Research Team in Universities of Tianjin, China (grant number: TD13-5078), and the National Natural Science Foundation of China (grant numbers: 41272245, 40972165, and 40572150).

Acknowledgments: The authors would like to express their gratitude to two anonymous reviewers for their insightful and constructive comments.

Conflicts of Interest: The authors declare no conflict of interest.

\section{References}

1. Civita, M.V. An improved method for delineating source protection zones for karst springs based on analysis of recession curve data. Hydrogeol. J. 2008, 16, 855-869. [CrossRef]

2. Plagnes, V.; Bakalowicz, M. The protection of karst water resources: The example of the Larzac karst plateau (south of France). Environ. Earth Sci. 2001, 40, 349-358. [CrossRef]

3. Mohammadi, Z.; Mahdavikia, H.; Raeisi, E.; Ford, D.C. Hydrogeological characterization of Dasht-e-Arjan Lake (Zagros Mountains, Iran): Clarifying a long-time question. Environ. Earth Sci. 2019, 78. [CrossRef]

4. Hao, Y.H.; Liu, G.L.; Li, H.M.; Li, Z.T.; Zhao, J.J.; Yeh, T.J. Investigation of Karstic Hydrological Processes of Niangziguan Springs (North China) Using Wavelet Analysis. Hydrol. Process. 2012, 26, 3062-3069. [CrossRef]

5. Zakhem, B.A.; Kattaa, B. Overexploitation and cumulative drought trend effect on Ras El Ain karstic spring discharge (Khabour Sub-basin, Syria). J. Earth Syst. Sci. 2017, 126. [CrossRef]

6. Swart, C.J.U.; James, A.R.; Kleywegt, R.J.; Stoch, E.J. The future of the dolomitic springs after mine closure on the Far West Rand, Gauteng, RSA. Environ. Earth Sci. 2003, 44, 751-770. [CrossRef]

7. Schrader, A.; Winde, F.; Erasmus, E. Using impacts of deep-level mining to research karst hydrology-A Darcy-based approach to predict the future of dried-up dolomitic springs in the Far West Rand goldfield (South Africa). Part 1: A conceptual model of recharge and inter-compartmental flow. Environ. Earth Sci. 2014, 72, 3549-3565. [CrossRef]

8. Panilas, S.; Petalas, C.P.; Gemitzi, A. The possible hydrologic effects of the proposed lignite open-cast mining in Drama lignite field, Greece. Hydrol. Process. 2008, 22, 1604-1617. [CrossRef]

9. Deb, P.; Kiem, A.S.; Willgoose, G. A linked surface water-groundwater modelling approach to more realistically simulate rainfall-runoff non-stationarity in semi-arid regions. J. Hydrol. 2019, 575, $273-291$. [CrossRef] 
10. Deb, P.; Kiem, A.S.; Willgoose, G. Mechanisms influencing non-stationarity in rainfall-runoff relationships in southeast Australia. J. Hydrol. 2019, 571, 749-764. [CrossRef]

11. Liang, Y.P.; Han, X.R.; Xue, F.H.; Li, L.X.; Zhang, W.Z. Water Resources Conservation for Karst Spring Basin of SHANXI Province; China Water and Power Press: Beijing, China, 2008.

12. Ozdemir, A. Defining groundwater resource protection zones in aquifers using stable isotope analysis: A case study from the Namazgah Dam Basin in Turkey. Environ. Earth Sci. 2019, 78. [CrossRef]

13. Sappa, G.; De Filippi, F.M.; Iacurto, S.; Grelle, G. Evaluation of Minimum Karst Spring Discharge Using a Simple Rainfall-Input Model: The Case Study of Capodacqua di Spigno Spring (Central Italy). Water 2019, 11, 807. [CrossRef]

14. Guo, Z.Z.; Zhang, H.D.; Yu, K.N. Multi-factor attenuation of karst springs in Shanxi province. Geo. Investig. Surv. 2004, 2, 22-25. (In Chinese)

15. Hao, Y.H.; Zhu, Y.; Zhao, Y.; Wang, W.; Du, X.; Yeh, T.J. The role of climate and human influences in the dry-up of the Jinci Springs, China. J. Am. Water Resour. Assoc. 2009, 45, 1228-1237. [CrossRef]

16. Li, X.; Shu, L.C.; Liu, L.H.; Yin, D.; Wen, J.M. Sensitivity analysis of groundwater level in Jinci Spring Basin (China) based on artificial neural network modeling. Hydrogeol. J. 2012, 20, 727-738. [CrossRef]

17. Sun, C.Z.; Wang, J.S.; Lin, X.Y. Research on the Jinci Spring's recovery after the use of water from the yellow river as municipal water supply. Carsologica Sin. 2001, 20,11-16. (In Chinese)

18. Shi, H.J.; Qi, X.; Jin, H. Prediction of karst groundwater level based on R-language-Taking Jinci Spring Basin as an example. Appl. Mech. Mater. 2015, 730, 230-234. [CrossRef]

19. Lv, C.M.; Ling, M.H.; Wu, Z.N.; Gu, P.; Guo, X.; Di, D.Y. Analysis of groundwater variation in the Jinci Spring area, Shanxi Province (China), under the influence of human activity. Environ. Geochem. Health 2019, 41, 921-928. [CrossRef]

20. Zhao, Y.G.; Cai, Z.H. Research on the Karst-Water System: Case Study of Taiyuan Area; Science Press: Beijing, China, 1990.

21. Liu, S.F.; Lin, Y. An Introduction to Grey Systems: Foundations, Methodology and Applications; IIGSS Academic Publisher: Slippery Rock, PA, USA, 1998.

22. Liu, S.F.; Lin, Y. Grey Information: Theory and Practical Applications; Springer: London, UK, 2006.

23. Hao, Y.H.; Yeh, T.J.; Gao, Z.Q.; Wang, Y.R.; Zhao, Y. A grey system model for studying the response to climatic change: The Liulin karst spring, China. J. Hydrol. 2006, 328, 668-676. [CrossRef]

24. Hao, Y.H.; Yeh, T.J.; Wang, Y.R.; Zhao, Y. Analysis of karst aquifer spring flows with a grey system decomposition model. Groundwater 2007, 45, 45-56. [CrossRef]

25. Hao, Y.H.; Wang, Y.J.; Zhu, Y.; Lin, Y.; Wen, J.C.; Yeh, T.J. Response of karst springs to climate change and anthropogenic activities: The Niangziguan Springs, China. Prog. Phys. Geogr. 2009, 33, 634-649. [CrossRef]

26. Li, W.W. Applying grey system theory to evaluate the relationship between industrial characteristics and innovation capabilities within Chinese high-tech industries. Grey Syst. Theor. Appl. 2016, 6, 143-168. [CrossRef]

27. Chen, J.J.; Zhang, R.; Liu, B. The empirical study of executive compensation in China port and shipping listed companies based on the grey relational analysis. Grey Syst. Theor. Appl. 2016, 6, 259-269. [CrossRef]

28. Xie, C.Y.; Feng, J.C.; Zhang, K.; Zhou, H.W.; Xue, S. Water use efficiency and influencing factors in the Mekong River Basin Region based on grey relational analysis. J. Grey Syst. 2018, 2, 28-41.

29. Liu, S.F. The Grey System Theory and Its Application, 8th ed.; Science Press: Beijing, China, 2017.

30. Zhao, J.J. Analysis of the Influence of Human Activities on the Spring Discharge in Jinci Springs. Master's Thesis, Tianjin Normal University, Tianjin, China, 2012. (In Chinese).

31. Zhong, Y.Y. Numerical Simulation Research on Influence of Channel Leakage in Fenhe River Upstream on Karst Groundwater in Jinci Spring Catchment. Master's Thesis, Taiyuan University of Technology, Taiyuan, China, 2017. (In Chinese).

32. Jin, H.; Yang, S.L.; Zheng, X.Q.; Li, C.J. Analysis of the Reduction in Flow from Jinci Springs. J. Taiyuan Univ. Technol. 2005, 36, 488-490. (In Chinese)

(C) 2019 by the authors. Licensee MDPI, Basel, Switzerland. This article is an open access article distributed under the terms and conditions of the Creative Commons Attribution (CC BY) license (http://creativecommons.org/licenses/by/4.0/). 